\title{
Review
}

Neuropsychobiology

Neuropsychobiology 2015;72:97-117

DOI: $10.1159 / 000441189$
Received: December 17, 2014

Accepted after revision: September 9, 2015 Published online: November 12, 2015

\section{Functional Neuroimaging in Psychopathy}

\author{
Antonio Del Casale ${ }^{a, b}$ Georgios D. Kotzalidis ${ }^{a}$ Chiara Rapinesi ${ }^{a, c}$ \\ Simone Di Pietro ${ }^{\text {a }}$ Maria Chiara Alessi ${ }^{a}$ Gianluigi Di Cesare ${ }^{d}$ Silvia Criscuolo ${ }^{a}$ \\ Pietro De Rossi ${ }^{a}$ Roberto Tatarelli ${ }^{a}$ Paolo Girardi ${ }^{a, c}$ Stefano Ferracuti ${ }^{\mathrm{e}}$ \\ a Department of Neuroscience, Mental Health and Sensory Organs (NESMOS), School of Medicine and Psychology, \\ Sapienza University, and Unit of Psychiatry, Sant'Andrea Hospital, Rome, ${ }^{b}$ Department of Psychiatric Rehabilitation, \\ San Francesco Institute, P. Alberto Mileno Onlus Foundation, Vasto, ' Department of Neuropsychiatry, Suore \\ Ospedaliere of the Sacred Heart of Jesus, Viterbo, ${ }^{\mathrm{d}}$ Department of Mental Health, ASL RM/E, Centro Diurno \\ Montesanto, and ' Department of Neurology and Psychiatry, Sapienza University, Rome, Italy
}

\section{Key Words}

Amygdala $\cdot$ Emotional processing $\cdot$ Functional neuroimaging · Prefrontal cortices · Psychopathy · Social functioning

\begin{abstract}
Background and Aim: Psychopathy is associated with cognitive and affective deficits causing disruptive, harmful and selfish behaviour. These have considerable societal costs due to recurrent crime and property damage. A better understanding of the neurobiological bases of psychopathy could improve therapeutic interventions, reducing the related social costs. To analyse the major functional neural correlates of psychopathy, we reviewed functional neuroimaging studies conducted on persons with this condition. Methods: We searched the PubMed database for papers dealing with functional neuroimaging and psychopathy, with a specific focus on how neural functional changes may correlate with task performances and human behaviour. Results: Psychopathy-related behavioural disorders consistently correlated with dysfunctions in brain areas of the orbitofrontallimbic (emotional processing and somatic reaction to emo-
\end{abstract}

tions; behavioural planning and responsibility taking), anterior cingulate-orbitofrontal (correct assignment of emotional valence to social stimuli; violent/aggressive behaviour and challenging attitude) and prefrontal-temporal-limbic (emotional stimuli processing/response) networks. Dysfunctional areas more consistently included the inferior frontal, orbitofrontal, dorsolateral prefrontal, ventromedial prefrontal, temporal (mainly the superior temporal sulcus) and cingulated cortices, the insula, amygdala, ventral striatum and other basal ganglia. Conclusions: Emotional processing and learning, and several social and affective decision-making functions are impaired in psychopathy, which correlates with specific changes in neural functions.

(c) 2015 S. Karger AG, Basel

\section{Introduction and Background}

\section{Introduction}

'Psychopathic' was used in Germany in the late 19th century to describe a person with aggressive and irresponsible behaviour [1]. However, the concept of psychopathy had its roots in France in the late 18th century:

\section{KARGER 125}

(c) 2015 S. Karger AG, Base

$0302-282 \mathrm{X} / 15 / 0722-0097 \$ 39.50 / 0$

E-Mail karger@karger.com

www.karger.com/nps
Prof. Antonio Del Casale, MD

Sant'Andrea Hospital, NESMOS Department

School of Medicine and Psychology, Sapienza University

Via di Grottarossa 1035-1039, IT-00189 Rome (Italy)

E-Mail antonio.delcasale@uniromal.it 
Pinel (1745-1826) described a person without a deficit in reasoning or judgement, but who was likely to break anything he would have within his reach, using the terms 'manie sans délire' and 'folie raisonnante' [2]. Pinel's followers focused on the personal unemotional and intellectually impaired side of the disorder rather than on its social aspects. Lombroso [3] and later Schneider [4] underlined the social impact of this disorder.

In 1941, Cleckley [5] well described the clinical profile of individuals with psychopathy, mainly characterised by superficial charm, absence of delusions and other signs of irrational thinking, absence of psychoneurotic manifestations, unreliability, lack of remorse or shame, inadequately motivated antisocial behaviour, poor judgement and failure to learn by experience, pathological egocentricity and incapacity for love, general poverty in major affective reactions, specific loss of insight, unresponsiveness in general interpersonal relations and uninviting behaviour with or without drink, who rarely carried out suicide and failed to follow any life plan.

From DSM-I, which reported the term sociopathic personality disturbance amidst personality disorders and distinguished between antisocial and dyssocial reactions [6], to DSM-5 [7], the problem of psychopathy was progressively considered in the context of the antisocial personality disorder (ASPD). With DSM-5, ASPD belongs to both disruptive, impulse control and conduct disorders as well as personality disorders, being fully described in the latter, while the term psychopathy has been reintroduced in the alternative DSM-5 model for criteria for personality disorders as ASPD to further pinpoint the psychopathology of people with this disorder (table 1) [7]. Psychopathic features became a specifier of ASPD, with the term meaning lack of anxiety or fear, and a bold interpersonal style that may mask fraudulence or other maladaptive behaviour. The 'primary psychopathic' patient shows low anxiety and withdrawal, and high attention seeking.

The above-mentioned epistemological problem has determined its consequences in the literature, where the use of the terms 'psychopathy' or 'ASPD' is somewhat arbitrary [8]. For example, the study by Tang et al. [9] used the label 'antisocial personality disorder' and recruited prison inmates (in a youth institution), whereas the studies by Veit et al. [10] and Birbaumer et al. [11] refer to 'psychopaths' for a group of prison inmates as well.

\section{Background}

Psychopathy manifests itself during development; it is characterised by emotional deficits, mainly including reduction in guilt and empathy, and an increased risk for exhibiting antisocial behaviour [12-15]. The question of whether criminal or aggressive behaviour is an essential part of the psychopathy construct is still unresolved [16, 17]. Psychopathy is estimated to affect about $1 \%$ (or less) of the general population $[18,19]$.

The orbitofrontal cortex (OFC) appeared to be involved in the expression of aggressive behaviour in both animal and human studies. A PET study by Pietrini et al. [20] showed OFC involvement in the expression of aggressive behaviour in healthy people. This led to the hypothesis that OFC dysfunction may correlate with dyscontrol of impulsive and aggressive behaviour in humans [20]. OFC involvement was also confirmed with a voxelbased MRI study by Matsuo et al. [21], who reported that small OFC volume correlated with high impulsivity, in line with previous data showing that the ventromedial prefrontal cortex (vmPFC) is involved in the modulation of impulsivity.

Emotional deficit characterises psychopathy and constitutes its most stable trait across age [14, 15, 22, 23]. Consistent with the hypothesis that psychopathic individuals show impairments in emotional learning and decision making, neuroimaging data showed decreased amygdala and OFC responses to emotionally provocative stimuli or during emotional learning paradigms in individuals with psychopathic tendencies [24]. A meta-analysis conducted on 43 structural/functional neuroimaging studies focused on antisocial, violent and psychopathic individuals showed consistent involvement of the OFC, dorsolateral frontal and anterior cingulate cortices (ACC) in antisocial behaviour [25].

The Psychopathy Checklist (PCL)-Revised (R) [26] is a 20-item, reliable and valid instrument used to assess psychopathy in both its categorical and dimensional aspects. It consists of two parts: (a) a semi-structured interview and (b) an individual history assessment. The second edition of the PCL-R includes 2 factor scores and 2 empirically resulting and validated facets for each of the 2 primary factors [12].

During assessment, the clinician scores 20 items that screen the modalities of the subject's interpersonal relationships, affective involvement, response to other people, response to situations, evidence of social deviance and lifestyle. The PCL-R also investigates selfish, insensitive victimization of others, and unstable and antisocial lifestyle. The total PCL-R score includes 2-factor and 4 -facet scores. Factor 1 includes interpersonal/affective problems, callousness and domination seeking, while factor 2 focuses on social deviance (antisocial/criminal lifestyle); the 4-facet model differentiates among affective,
98

Neuropsychobiology 2015;72:97-117 DOI: $10.1159 / 000441189$
Del Casale et al. 
Table 1. Comparison of DSM-IV-TR/DSM-5 criteria for antisocial personality disorder and proposed criteria in the context of the Alternative DSM-5 Model for Personality Disorders [7]

Antisocial Personality Disorder, Diagnostic Criteria 301.7 (F60.2)
Alternative DSM-5 Model for Personality Disorders: Criteria for ASPD
A A pervasive pattern of disregard for and violation of the rights of others, occurring since age 15 years, as indicated by three (or more) of the following:

1 Failure to conform to social norms with respect to lawful behaviours, as indicated by repeatedly performing acts that are grounds for arrest

2 Deceitfulness, as indicated by repeated lying, use of aliases, or conning others for personal profit or pleasure

3 Impulsivity or failure to plan ahead

4 Irritability and aggressiveness, as indicated by repeated physical fights or assaults

5 Reckless disregard for safety of self or others

6 Consistent irresponsibility, as indicated by repeated failure to sustain consistent work behaviour or honour financial obligations

7 Lack of remorse, as indicated by being indifferent to or rationalizing having hurt, mistreated, or stolen from another

B The individual is at least age 18 years

C There is evidence of conduct disorder with onset before age 15 years

D The occurrence of antisocial behaviour is not exclusively during the course of schizophrenia or bipolar disorder
A Moderate or greater impairment in personality functioning, manifested by characteristic difficulties in two or more of the following four areas:

1 Identity: Egocentrism; self-esteem derived from personal gain, power, or pleasure

2 Self-direction: Goal setting based on personal gratification; absence of prosocial internal standards, associated with failure to conform to lawful or culturally normative ethical behaviour

3 Empathy: Lack of concern for feelings, needs, or suffering of others; lack of remorse after hurting or mistreating another

4 Intimacy: Incapacity for mutually intimate relationships, as exploitation is a primary means of relating to others, including by deceit and coercion; use of dominance or intimidation to control others

B Six or more of the following seven pathological personality traits:

1 Manipulativeness (an aspect of Antagonism): Frequent use of subterfuge to influence or control others; use of seduction, charm, glibness, or ingratiation to achieve one's ends

2 Callousness (an aspect of Antagonism): Lack of concern for feelings or problems of others; lack of guilt or remorse about the negative or harmful effects of one's actions on others; aggression; sadism

3 Deceitfulness (an aspect of Antagonism): Dishonesty and fraudulence; misrepresentation of self; embellishment or fabrication when relating events

4 Hostility (an aspect of Antagonism): Persistent or frequent angry feelings; anger or irritability in response to minor slights and insults; mean, nasty, or vengeful behaviour

5 Risk taking (an aspect of Disinhibition): Engagement in dangerous, risky, and potentially self-damaging activities, unnecessarily and without regard for consequences; boredom proneness and thoughtless initiation of activities to counter boredom; lack of concern for one's limitations and denial of the reality of personal danger

6 Impulsivity (an aspect of Disinhibition): Acting on the spur of the moment in response to immediate stimuli; acting on a momentary basis without a plan or consideration of outcomes; difficulty establishing and following plans

7 Irresponsibility (an aspect of Disinhibition): Disregard for - and failure to honour financial and other obligations or commitments; lack of respect for - and lack of follow-through on - agreements and promises

Note: The individual is at least 18 years of age. Specify if: With psychopathic features. Specifiers. A distinct variant often termed psychopathy (or 'primary' psychopathy) is marked by a lack of anxiety or fear and by a bold interpersonal style that may mask maladaptive behaviours (e.g., fraudulence). This psychopathic variant is characterized by low levels of anxiousness (Negative Affectivity domain) and withdrawal (Detachment domain) and high levels of attention seeking (Antagonism domain). High attention seeking and low withdrawal capture the social potency (assertive/dominant) component of psychopathy, whereas low anxiousness captures the stress immunity (emotional stability/resilience) component. In addition to psychopathic features, trait and personality functioning specifiers may be used to record other personality features that may be present in antisocial personality disorder but are not required for the diagnosis. For example, traits of Negative Affectivity (e.g., anxiousness) are not diagnostic criteria for antisocial personality disorder (see Criterion B) but can be specified when appropriate. Furthermore, although moderate or greater impairment in personality functioning is required for the diagnosis of antisocial personality disorder (Criterion A), the level of personality functioning can also be specified interpersonal and antisocial lifestyle, and criminal history facets $[12,26]$. The PCL Screening Version (SV) consists of 12 items developed to assess psychopathy in civic or forensic settings [27].

This paper aimed to review functional neuroimaging studies focused on individuals with psychopathy. Con- sidering the lack of well-defined and widely accepted criteria for differential diagnosis between psychopathy and ASPD, our paper focuses on functional neuroimaging studies that specifically assessed psychopathy with the PCL-R (SV) in order to analyse the principal neural functional changes correlating with this condition. 


\section{Method}

We searched the PubMed database for the terms psychopathy, functional magnetic resonance imaging (fMRI), magnetic resonance spectroscopy (MRS), magneto-encephalography (MEG), near-infrared spectroscopy (NIRS), positron emission tomography (PET) and single-photon emission computed tomography (SPECT).

Papers were included if they satisfied standards for adequate methodology and population included, and had focused on psychopathy, as assessed with the PCL-R (SV).

Exclusion criteria comprised unspecified or inadequately described methodology, not reporting data of psychopathy, not using the PCL-R (SV), comorbid psychiatric disorder(s), comorbid current substance use disorder, studies focused on drug craving or children/adolescents, studies pooling together people with psychopathy/ASPD and psychiatric disorders, studies not published in peer-reviewed journals (or those in peer-reviewed journals that are found in non-peer-reviewed, industry-sponsored supplements) and studies with a sample size of psychopaths smaller than 5 .

We searched for the following terms in PubMed (title or abstract): ('psychopathy' OR 'antisocial personality disorder') AND ('functional magnetic resonance' OR 'fMRI' OR 'magneto-encephalography' OR 'MEG' OR 'near-infrared spectroscopy' OR 'NIRS' OR 'single photon' OR 'positron' OR 'PET' OR 'spectroscop*').

Further papers that did not appear in the above database were searched from reference lists of retrieved papers and from other web sources, adding search terms related to offending behaviour, violence and aggression. We thereafter conceptually checked all retrieved papers for appropriateness and excluded duplicates and irrelevant studies (unfocused with respect to our review).

Then we analysed the remaining papers for eligibility on the basis of our inclusion and exclusion criteria. The papers included on the basis of these criteria were analysed and discussed according to the PRISMA statement [28].

Koenigs et al. [29] underlined the considerable variability in results across studies focused on psychopathy, and the problem of related methodological issues (i.e. the use of between-group as well as correlational analyses, different assessments of psychopathy and consideration of psychopathic subtypes, and use of different methodologies/tasks in functional neuroimaging studies). Taking into account these methodological issues, the discussion of the present article is focused on neuroimaging data obtained during the resting state and while performing specific task sets.

We performed a critical overview of all studies included.

\section{Results}

Our PubMed search strategy yielded 72 papers in May 11, 2015.

We found a further 15 papers from other web sources and reference lists of retrieved papers; thus, the total number of papers to evaluate amounted to 87, of which 1 paper was a duplicate. Of the remaining 86 , we excluded a further 15 articles because they were not relevant to our review. We then analysed the remaining 71 papers for eligibility on the basis of our inclusion and exclusion criteria. We excluded 43 studies, of which 22 did not assess psychopathy with PCL-R, 8 were reviews, 2 focused on children, 2 on substance abuse/craving, 5 on other diagnoses or conditions, 2 on different diagnoses and comorbidities, and 2 had psychopathy samples smaller than 5 .

On the basis of these criteria, this review finally comprised 28 papers dealing with functional neuroimaging in psychopathy published in peer-reviewed scientific journals from 1997 to 2015 (see fig. 1 - PRISMA flow diagram).

\section{Functional Neuroimaging Techniques}

One study used SPECT, 1 MRS and 26 studies used blood oxygen level-dependent (BOLD) fMRI.

The main results are listed in table 2 , specifying methods, results and conclusions for each study included in this review. We summarised the different tasks and their categorisation in table 3.

\section{Discussion}

\section{Resting State}

A specific set of brain regions is engaged when individuals are left to think to themselves undisturbed. This set is called 'default mode network' (DMN) and is active when individuals are engaged in internally focused tasks, including autobiographical memory retrieval, envisioning the future and conceiving the perspectives of others [30]. We can describe this network in terms of multiple interacting subsystems: a medial temporal lobe subsystem (memories and associations) and a medial prefrontal subsystem (use of memories and associations with production of 'self-relevant mental simulations'). In this context, the posterior cingulate cortex (PCC) is a main node of integration [30].

Different studies have assessed brain function comparing subjects with psychopathy and controls during a resting state condition. Results showed brain activation changes in the vmPFC, precuneus and PCC [31], and connectivity changes in frontal areas [32].

The precuneus/PCC and vmPFC comprise the DMN major midline structures [33-36], and human lesion studies have long implicated vmPFC dysfunction in the pathogenesis of psychopathic behavioural and affective traits [37-40]. Motzkin et al. [31] showed that right anterior vmPFC activation is significantly less correlated with right amygdala activation in psychopaths than in non- 
Fig. 1. PRISMA flow diagram showing the search and inclusion strategy.

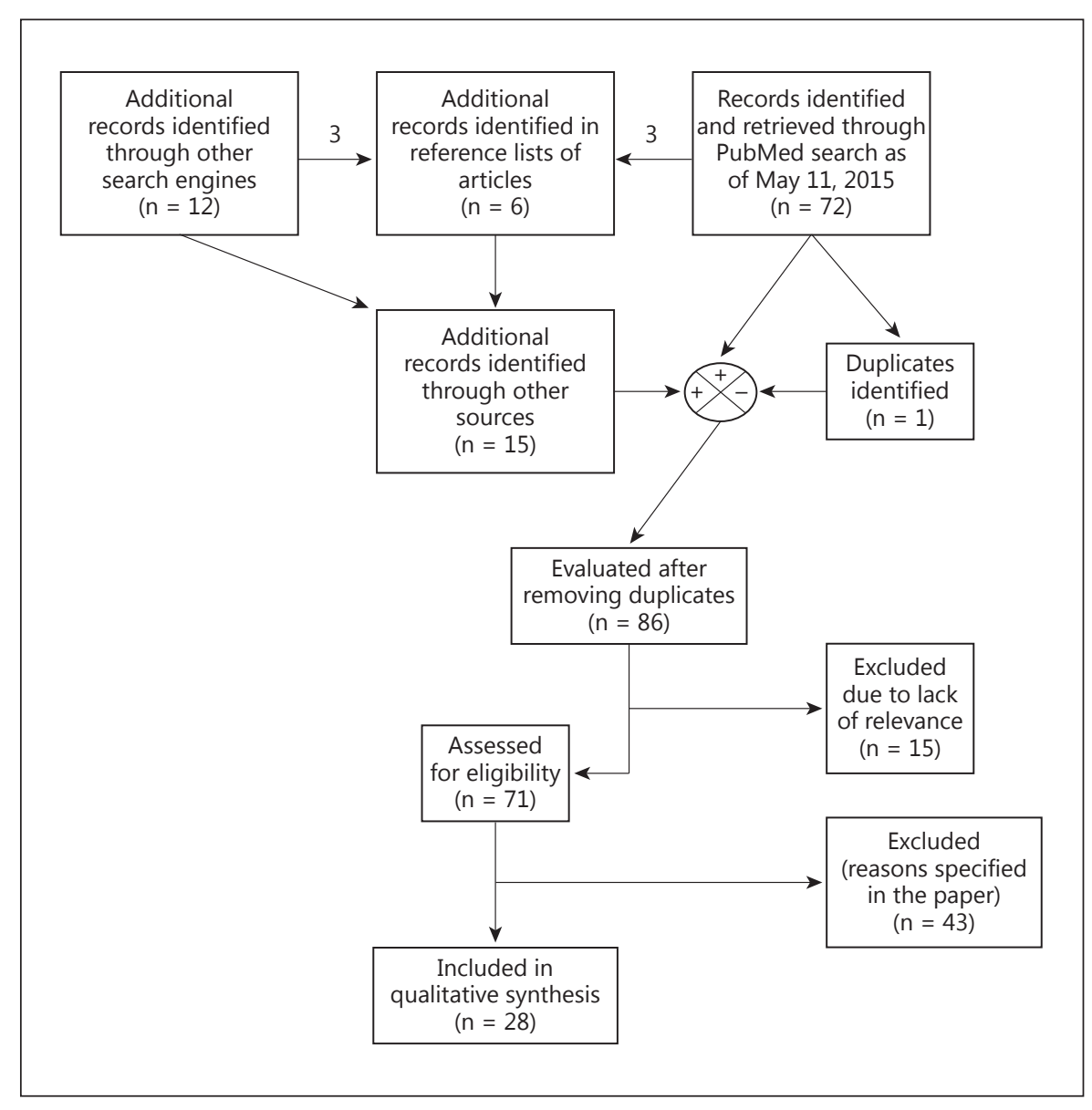

psychopaths, supporting an association between psychopathic traits and reduced vmPFC-amygdala functional connectivity. The same authors also computed resting BOLD correlations with a seed region located in the right precuneus/PCC, finding a cluster of voxels in the right anterior vmPFC exhibiting significantly lower correlation with the right precuneus/PCC in psychopaths than in non-psychopaths, as well as a cluster in more posterior vmPFC extending to the subgenual area and part of the rostral ACC [31]. They also suggested that vmPFC-amygdala functional connectivity can distinguish psychopaths from non-psychopaths and primary (low-anxious) from secondary (high-anxious) psychopaths [31]. These findings provide evidence for a dissociability of the neural substrates of the different subtypes of psychopathy.

A functional connectivity study showed that besides hypoactivation of a 'moral judgement circuitry' in psychopaths during moral task performance, there was a lack of integration between cognitive and emotional circuits subserving moral judgement, which was present also at the resting state [32]. This study found reduced reciprocal connectivity strengths between long circuits in the face of the preservation of connectivity strength between areas united through short tracts. In particular, frontal areas showed reduced connectivity with the PCC and nearby visual areas, and, reciprocally, the PCC showed reduced functional connectivity with frontal cortical areas, namely with the medial frontal lobe, but also extending to the ventrolateral (vlPFC) and dorsolateral PFC (dlPFC).

Resting-state ACC dysfunction correlated with psychopathy. The ACC N-acetyl-aspartate/creatine ratio correlated inversely with both the total PCL-R score and the score on the PCL-R factor 1 among adult male military conscripts with psychopathy in an MRS study by Basoglu et al. [41], suggesting that a neural integrity impairment in the ACC may worsen the lack of interpersonal and emotional/affective skills in psychopathy.

The involvement of the left dorsal ACC and left insular cortex has also been stressed by Ly et al. [42], who reported reduced functional connectivity between these areas in 


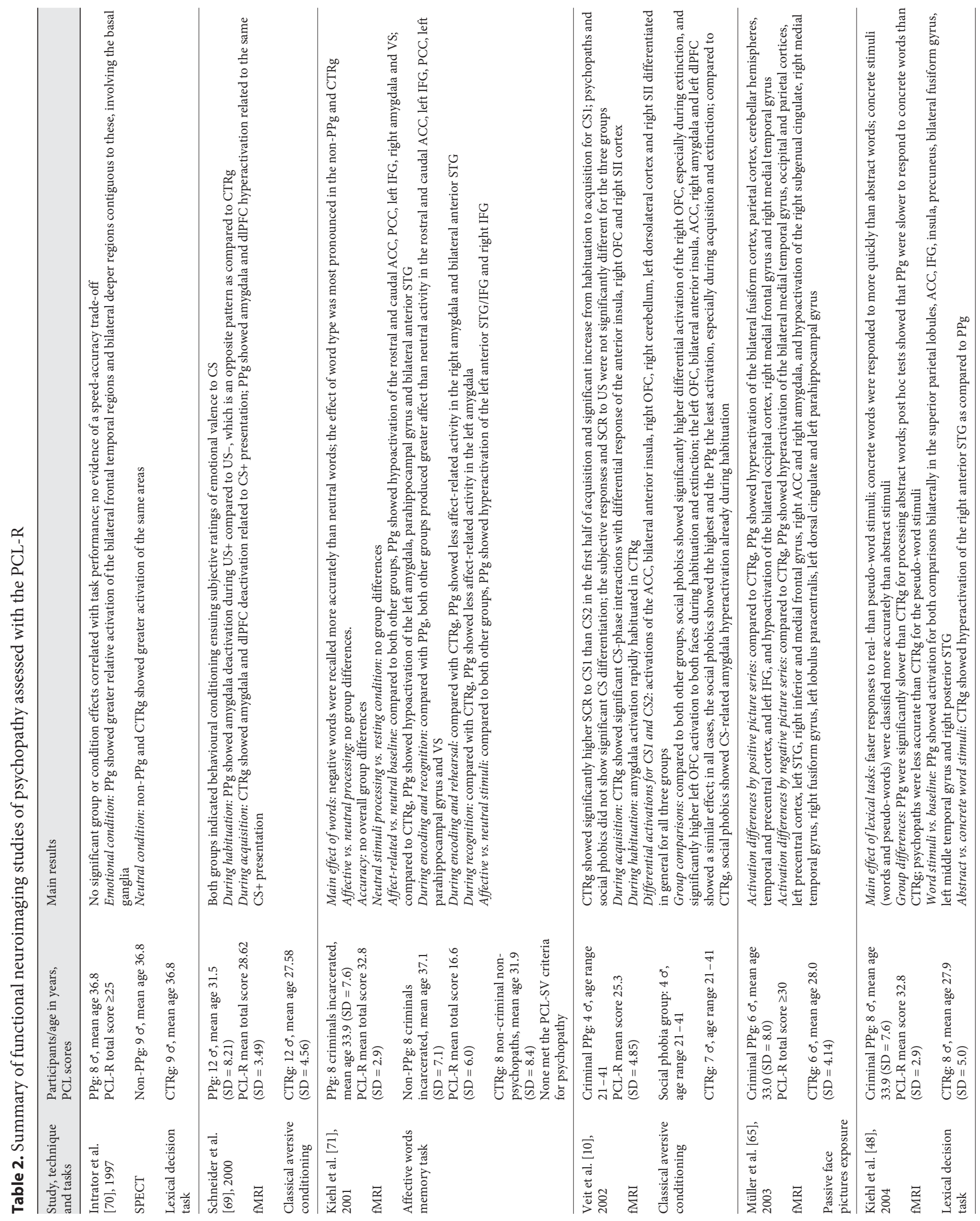




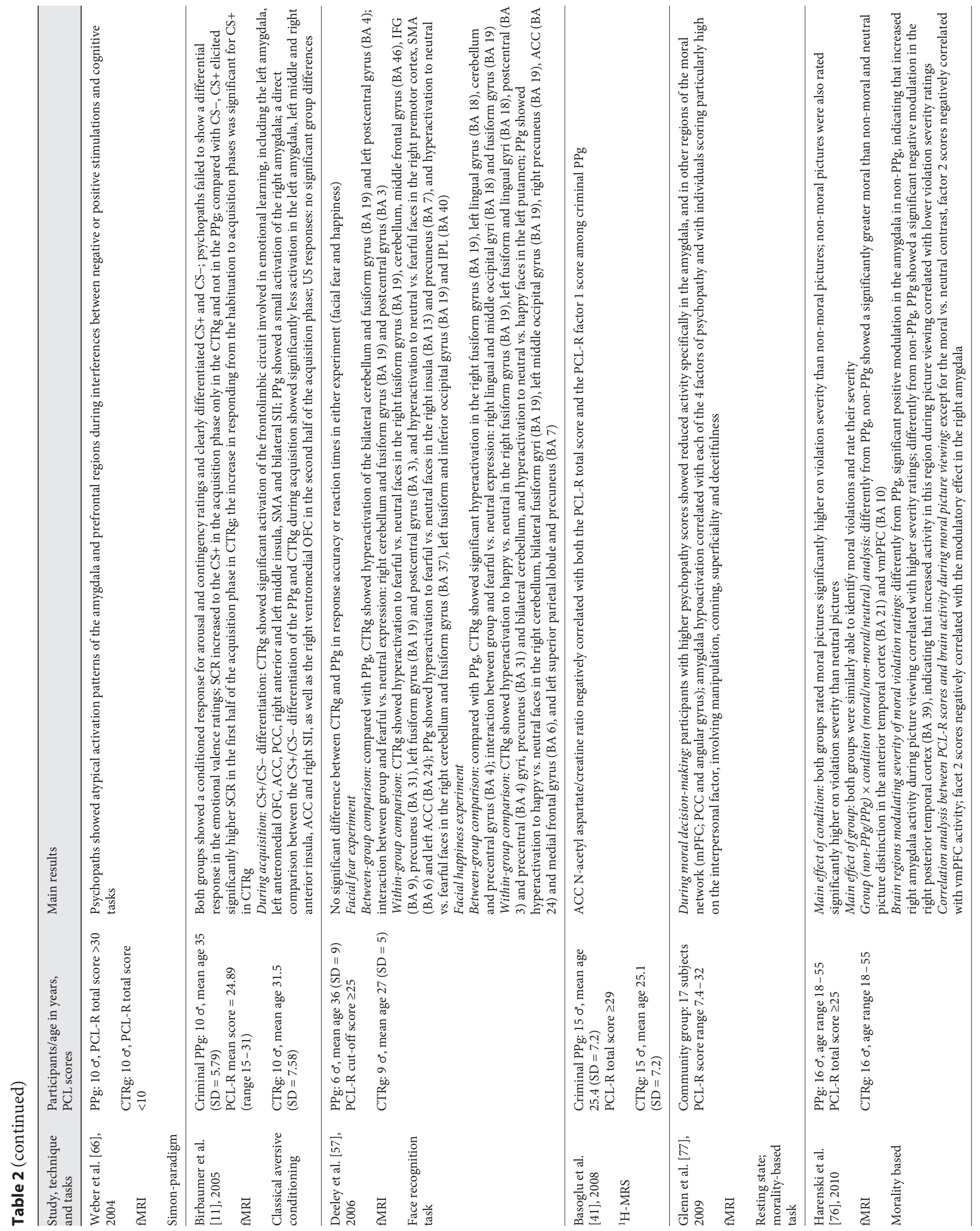




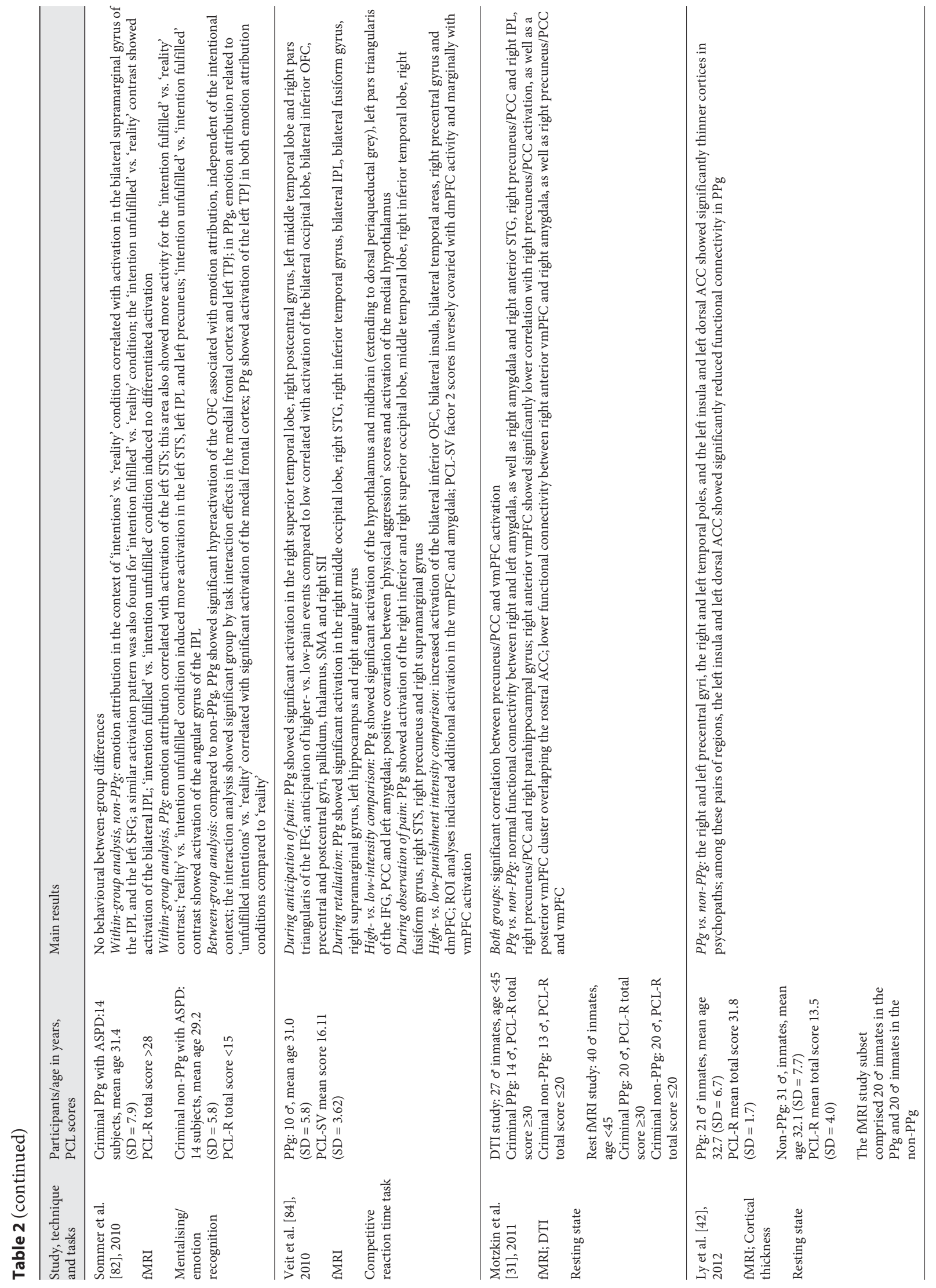




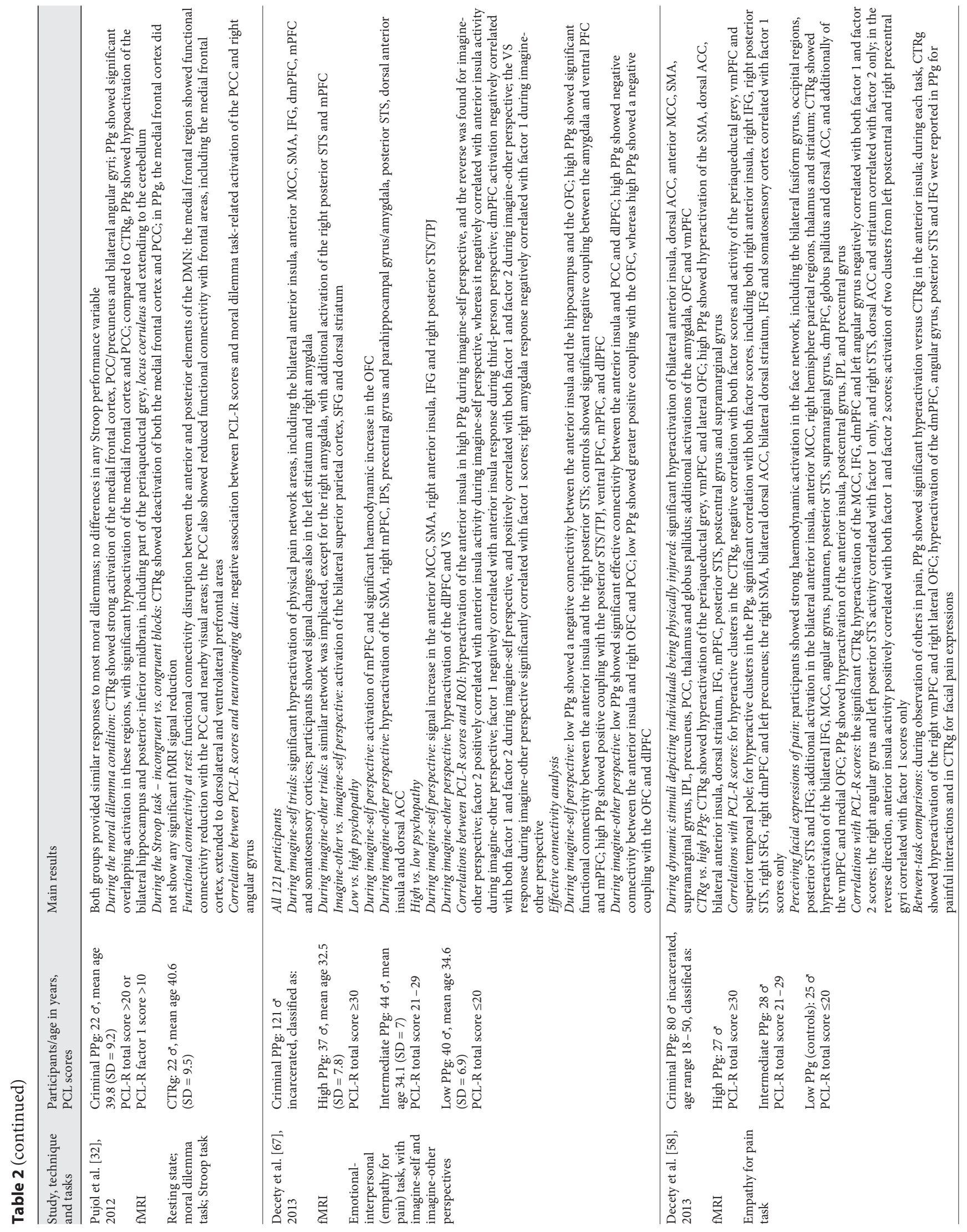




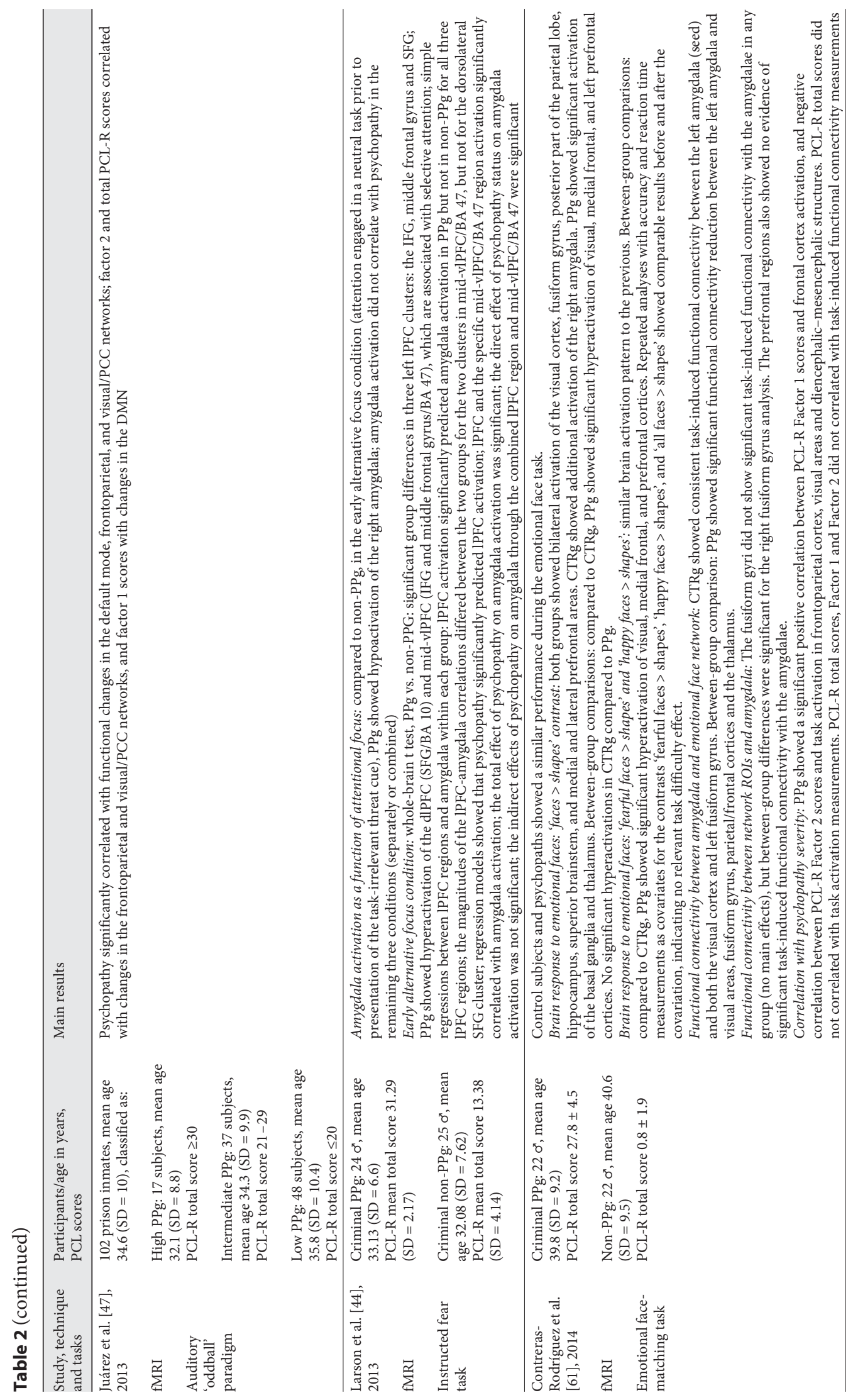




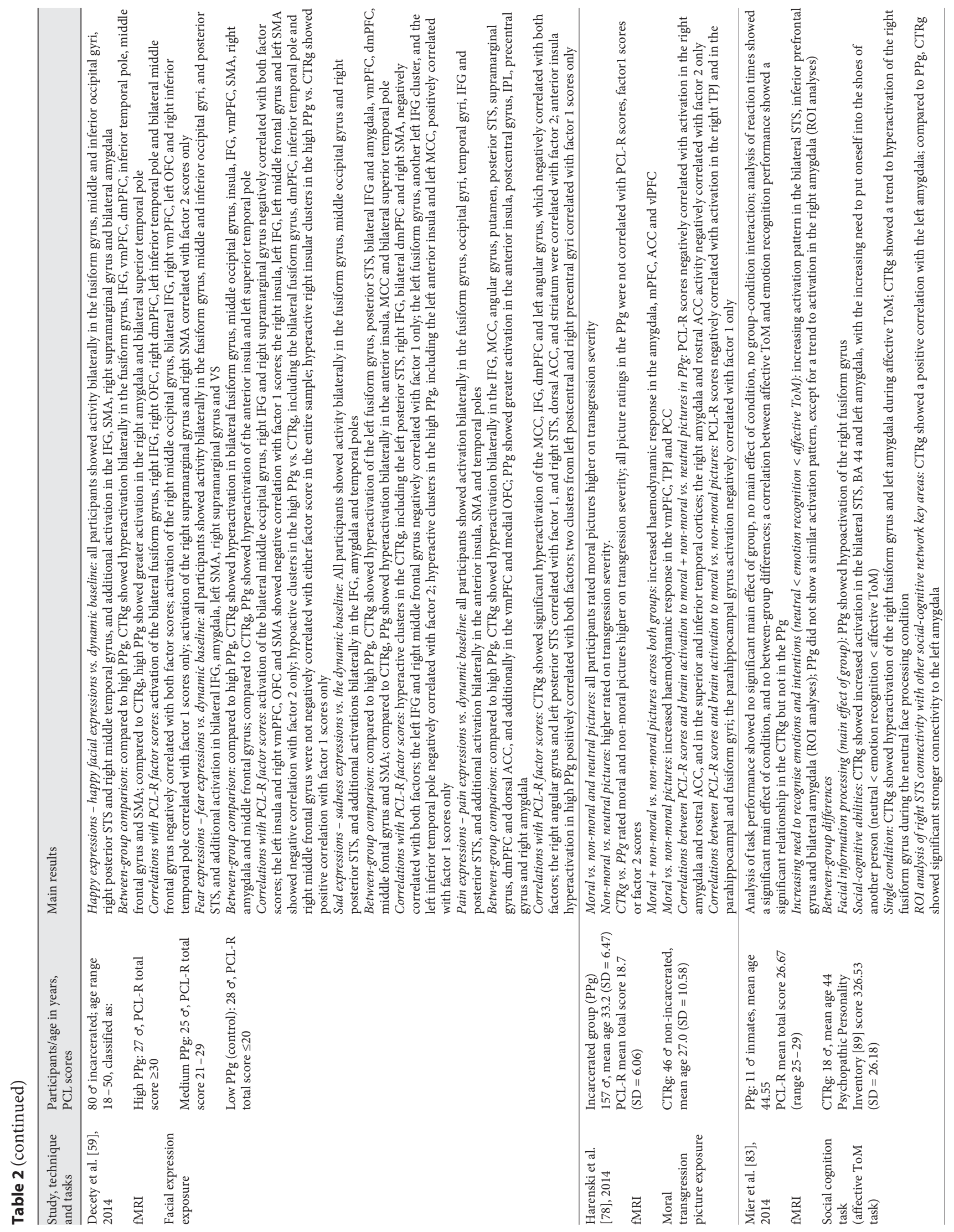




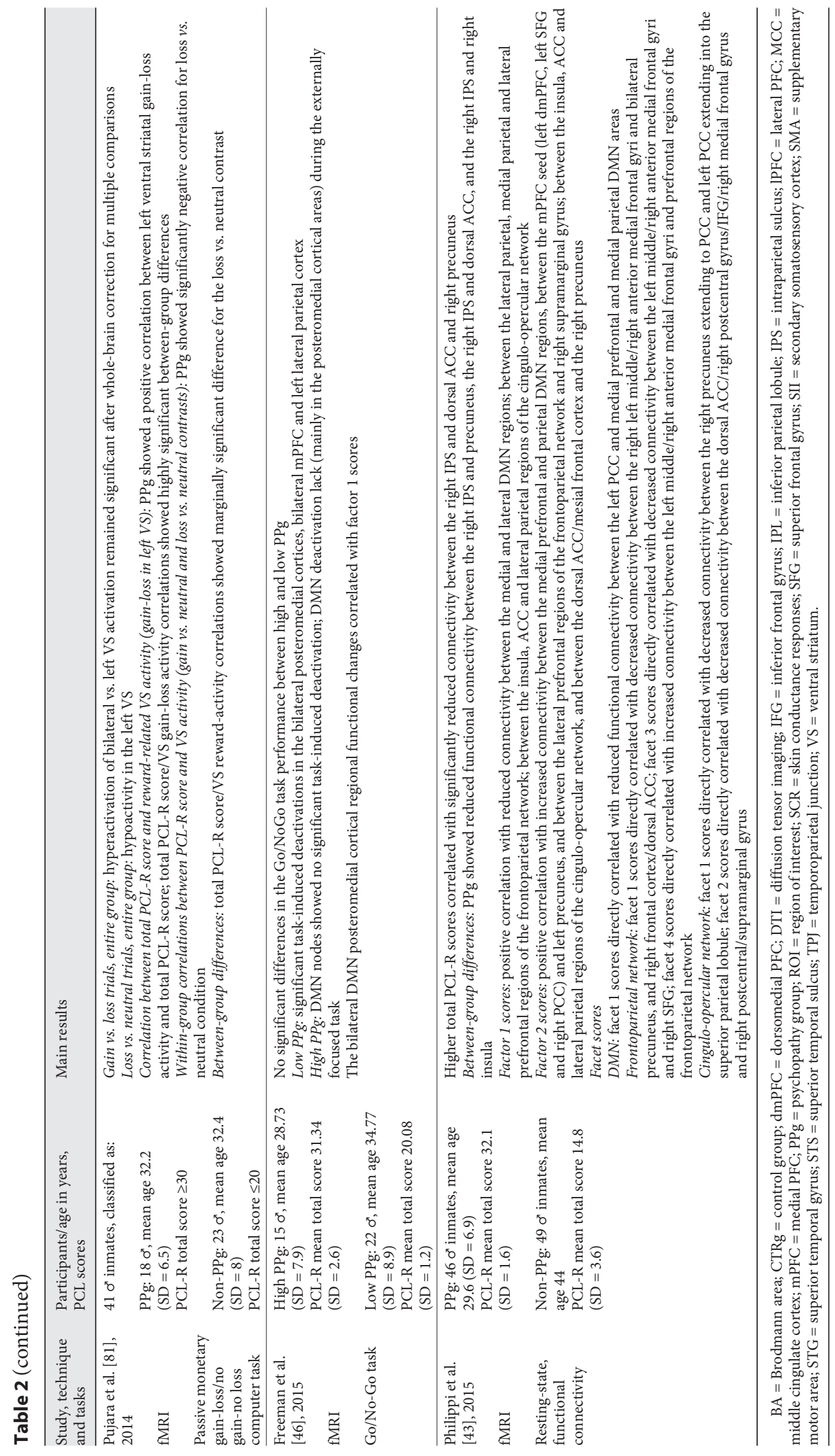


Table 3. Summary of adopted tasks in functional neuroimaging studies of psychopathy

\begin{tabular}{|c|c|c|}
\hline Task category & Specific tasks & Study \\
\hline Resting state & & $\begin{array}{l}\text { Basoglu et al. [41], } 2008 \\
\text { Glenn et al. [77], } 2009 \\
\text { Motzkin et al. [31], } 2011 \\
\text { Ly et al. [42], 2012 } \\
\text { Pujol et al. [32], 2012 } \\
\text { Philippi et al. [43], } 2015\end{array}$ \\
\hline $\begin{array}{l}\text { Attentional functions } \\
\text { and reaction time }\end{array}$ & $\begin{array}{l}\text { Stroop } \\
\text { Auditory target detection 'oddball' } \\
\text { Instructed fear } \\
\text { Go/NoGo } \\
\text { Lexical decision (non-emotional) }\end{array}$ & $\begin{array}{l}\text { Pujol et al. [32], } 2012 \\
\text { Juárez et al. [47], } 2013 \\
\text { Larson et al. [44], } 2013 \\
\text { Freeman et al. [46], } 2015 \\
\text { Kiehl et al. [48], 2004 }\end{array}$ \\
\hline \multicolumn{3}{|l|}{ Emotional tasks: } \\
\hline Facial exposure & $\begin{array}{l}\text { Facial expression exposure } \\
\text { Pain interaction and expression tasks } \\
\text { Dynamic facial expression exposure } \\
\text { Emotional face matching }\end{array}$ & $\begin{array}{l}\text { Deeley et al. [57], } 2006 \\
\text { Decety et al. [58], } 2013 \\
\text { Decety et al. [59], } 2014 \\
\text { Contreras-Rodríguez et al. [61], } 2015\end{array}$ \\
\hline Picture exposure & $\begin{array}{l}\text { Neutral, negative and positive emotional picture exposure } \\
\text { Neutral, negative and positive emotional picture exposure } \\
\text { Empathy for pain }\end{array}$ & $\begin{array}{l}\text { Müller et al. [65], } 2003 \\
\text { Weber et al. [66], } 2004 \\
\text { Decety et al. [67], } 2013\end{array}$ \\
\hline Conditioning & $\begin{array}{l}\text { Pavlovian classical aversive conditioning } \\
\text { Pavlovian classical aversive conditioning } \\
\text { Pavlovian classical aversive conditioning } \\
\text { Lexical decision } \\
\text { Affective words memory }\end{array}$ & $\begin{array}{l}\text { Schneider et al. [69], } 2000 \\
\text { Veit et al. [10], 2002 } \\
\text { Birbaumer et al. [11], } 2005 \\
\text { Intrator et al. [70], } 1997 \\
\text { Kiehl et al. [71], 2001 }\end{array}$ \\
\hline Morality & $\begin{array}{l}\text { Moral dilemma } \\
\text { Moral dilemma } \\
\text { Moral dilemma } \\
\text { Moral contrast }\end{array}$ & $\begin{array}{l}\text { Glenn et al. [77], 2009 } \\
\text { Harenski et al. [76], } 2010 \\
\text { Pujol et al. [32], 2012 } \\
\text { Harenski et al. [78], } 2014\end{array}$ \\
\hline Reward & Monetary gain/loss & Pujara et al. [81], 2014 \\
\hline Social cognition & $\begin{array}{l}\text { Social cognition } \\
\text { Competitive reaction time (retaliation) } \\
\text { Social cognition }\end{array}$ & $\begin{array}{l}\text { Sommer et al. [82], } 2010 \\
\text { Veit et al. [84], 2010 } \\
\text { Mier et al. [83], } 2014\end{array}$ \\
\hline
\end{tabular}

psychopathic versus non-psychopathic individuals. Dorsal ACC-insular dysfunction, which is viewed as a cingulo-opercular network impairment, is reciprocally related to scores on the 2 PCL-R factors, in that reduced connectivity is correlated with higher scores on factor 1 and increased connectivity is correlated with higher scores on factor 2 [43]. This network may relate to deficits in empathy, salience detection and cognitive control. The same dysfunction can be viewed in the context of the DMN activity, which is related to internally directed attention, and of the frontoparietal network activity, which is linked to externally directed attention [43]. Reduced parietaldorsal ACC connectivity has been viewed as a main correlate of psychopathy in the study by Philippi et al. [43].
The connectivity dysfunctions between these two areas may relate to deficits in directing attention to salient stimuli in psychopathy.

\section{Attention- and Reaction Time-Assessing Tasks}

Larson et al. [44] conducted an fMRI study with an instructed fear task, mainly focusing on attention-related circuitry in psychopathic offenders. The authors reported that differences in amygdala activation in subjects with psychopathy are a function of goal-directed attention (for example, focus of attention can moderate amygdala dysfunction in psychopathy). The same study reported that regions of lateral PFC (relatives to top-down attention) mediate the correlation between psychopathy and amyg- 
dala activation [44]. This can confirm the central role of top-down attention in regulating bottom-up emotion and inhibitory cues in psychopathic offenders. This study also showed a tendency of people with psychopathy to focus on primary goals and tasks, excluding goal-irrelevant information. The activation of the mid-vlPFC can be a neural functional correlate of such inflated selective attention in psychopathic offenders [44].

Patients with bipolar disorder hyperactivate their vlPFC when exposed to emotional tasks [45]; interestingly, goal directedness is one of the symptoms found in bipolar disorder during the manic phase, so the inability to deactivate the vlPFC might represent a common pathway of this symptom to manifest itself in both disorders. The dysfunctional recruitment of the amygdala in response to relevant emotional cues (during the pursue of immediate goals) may be related to a more general 'lateral PFC-instantiated attention bottleneck' that results in the peripheral information processing deficit [44].

The Go/NoGo task consists in the exposure to computer-generated visual stimuli displayed on a screen for discrete time intervals, to which the participant is required to respond by pressing (Go) or not pressing a button (NoGo) and can be used to measure his/her sustained attention and control over the response (i.e. the ability to suppress a prepotent response). Freeman et al. [46] conducted an fMRI study to assess DMN activation during a Go/NoGo task in a group of 22 high-psychopathy and 22 low-psychopathy prisoners. They reported that both the low-psychopathy group and the non-prison healthy subject group exhibited task-related DMN deactivation, whereas the high-psychopathy group failed to deactivate any DMN subregions, particularly regarding the medial frontal cortex. This failure to deactivate the DMN could be related to increased self-focus, reduced empathy and deficits in attention-related processes. The authors found a specific correlation between medial prefrontal dysfunction and PCL-R factor 1 scores (affective and interpersonal deficits in criminal psychopaths) [46].

The fMRI study by Juárez et al. [47] with an oddball paradigm suggested that functional connectivity abnormalities in the ACC and PCC may relate to deficits in internal monitoring of cognitive and attentional processes, which are more linked to factor 1 scores. Factor 2 scores were more linked to frontoparietal dysfunction than factor 1, suggesting that this dysfunction is more strongly linked to the impulsive than to the affective dimension of psychopathy [47].

Psychopathy has been correlated with slower reaction times when processing abstract word stimuli and poor ac- curacy in classifying pseudoword stimuli [48]. The fMRI study by Kiehl et al. [48] showed that psychopathy correlated to activation deficits in the right anterior superior temporal and nearby cortex for processing abstract stimuli. Although the pattern of neural activation in this region did not differ between individuals with psychopathy and healthy controls, the former failed to show the appropriate differential neural activation occurring normally between abstract and concrete stimulus exposure. The authors hypothesised that the neural functional changes in the semantic networks may be linked to a failure to incorporate contextual cues related to emotional and abstract concepts, and may lead to psychopathic behaviours. In brief, this theory considered right hemisphere abnormalities and related impaired processing of conceptually abstract material as a core deficit in psychopathy [48].

\section{Emotional Tasks}

Blair [49] theorised that specific deficits in experiencing fear and sadness are linked to the development of psychopathy. Dadds et al. [50] correlated dysfunctions in attentional mechanisms with emotion recognition deficits. Newman and Lorenz [51] formulated the 'response modulation hypothesis' that considers the emotional response in psychopathy as potentially appropriate when processing information regarding the primary attentional focus. However, when one needs to appraise peripheral information with respect to the latter, affective information processing becomes dysfunctional. We here expose the main functional neuroimaging data relating to these two theories.

\section{Facial-Exposure Tasks}

Facial expressions communicate intra- and interspecies social information. For Darwin, this communication is vital in group-dwelling species [52]. The amygdala is one of the main brain regions involved in facial recognition of fear and negative emotions [53]. Other cortical and subcortical areas, including the basal ganglia, OFC and insular, occipitotemporal and right frontoparietal cortices are involved in these processes [54].

Functional neuroimaging analysed face recognition in individuals with psychopathy and/or ASPD through adult face pictures from the facial affect series [55], the Montreal set of facial displays of emotion [56] and standardised series of prototypical facial expressions posed by volunteers [57].

Deeley et al. [57] subjected psychopaths and healthy controls to an emotional face recognition task involving 
fearful versus happy versus neutral faces. Psychopaths showed significantly less activation than controls in fusiform and extrastriate cortices when processing both fearful and happy faces. Upon exposure to fearful versus neutral faces, the psychopaths responded with deactivation of the fusiform gyrus, while controls responded with hyperactivation [57]. Exposure to happy faces was associated with hyperactivation of fusiform and extrastriate cortices in both groups, but the activation was significantly lower in psychopaths. This study demonstrated that individuals with psychopathic traits differently process facial emotional expressions, and that the type of emotion affected the response pattern [57].

Decety et al. [58] combined a pain interaction-expression task with fMRI and found a wide involvement of the anterior insula in psychopathy, showing involvement of the orbital PFC and vmPFC as well, which was related to ongoing behavioural monitoring, estimation of consequences and emotional learning.

A major neural functional correlate of psychopathy during the perception of others in pain is a lack of engagement of regions in the brainstem and OFC/vmPFC; the integrative function of these two areas is essential for representations with an affective value, in particular those that are related to a reward/punishment meaning of an object or another entity $[58,59]$.

Decety et al. [59] used fMRI and exposed male inmates to fearful, sad, happy and painful faces; OFC and vmPFC were consistently hypoactivated in psychopathy. Their findings did not support a particular dysfunction in fear perception, but were rather in line with hypotheses of pervasive emotional deficits in psychopathy $[13,60]$.

During an emotional face-matching task, psychopathy also correlated with hyperactivation of neocortical areas, including both visual cortices and PFC and with decreased task-induced functional connectivity between the amygdala and the PFC and visual cortices [61]. This neural functional pattern suggested that differences in the neural processing of emotional faces may correlate with both deficient (implicit limbic) and compensatory (neocortical) mechanisms, and that implicit limbic system engagement is disrupted in psychopathy [61].

\section{Picture Exposure}

Looking at pictures with emotional content without being asked to recognise the emotion can be a powerful tool to activate brain structures involved in emotional processing. Neurophysiological studies showed that emotionally charged pictures successfully evoked a variety of measurable emotional reactions [62-64].

Functional Neuroimaging in Psychopathy
Müller et al. [65] showed increased activation of the OFC, dlPFC, right amygdala and right insula upon exposure to negative pictures in individuals with psychopathy compared to controls. This supported the hypothesis of a dysfunctional top-down modelling effect via OFC and amygdala in psychopathy [65]. The same study reported hyperactivation (and correlates of psychopathy) of the right amygdala (processing of negative emotions), hippocampus (processing and regulation of emotions, and memory consolidation) and left temporal cortex (arousal regulation), while reporting hypoactivation of the right temporal cortex (arousal regulation). Functional changes in temporal cortices supported a dysfunctional lateralisation of arousal regulation in psychopathy [65].

Another fMRI study involved interference of negative, positive or neutral stimuli with cognitive task performance and showed psychopathy to correlate with abnormal activation in the amygdala and PFC, believed to underlie dysregulation of emotion-cognition interaction in psychopathy [66].

Decety et al. [67] carried out an fMRI study using the empathy for others' pain paradigm. They exposed inmates to stimuli depicting bodily injuries, asking participants to imagine-self and imagine-other perspectives. Highest haemodynamic responses were found in the anterior insula and anterior middle cingulate cortex (regions related to affective components of empathy) in high PCL-R-scoring psychopaths during the imagine-self perspective task, indicating that emotional resonance in psychopathy is not significantly reduced in the context of the first-person perspective with respect to healthy controls. Psychopathic traits inversely correlated with the activity of the anterior insula during the imaging-other-in-pain perspective, indicating that more vicarious experience was elicited in controls, and the opposite pattern (low anterior insula activation) was found in the high-psychopathy group [67]. Furthermore, right amygdala functional changes were shown during the imagine-self perspective in all participants and during the imagine-other perspective in controls. Haemodynamic responses in the amygdala correlated inversely with PCL-R factor 1 scores during the imagine-other perspective, suggesting that psychopaths lack the ability to respond to distress cues and are insensitive to others' vulnerability [67]. The same study underlined that amygdala-OFC interactions are related to the outcome of perspective taking in psychopathy. People with psychopathy elicit amygdala-OFC coupling during the imagine-self perspective, but not during the imagine-other one. OFC recruitment failure during the imagine-other perspective taking supports dysfunc-

Neuropsychobiology 2015;72:97-117 111 
tion of this neural pathway in response to distress cues of others in psychopaths [67].

Decety et al. [67] also reported that factor 1 scores predicted ventral striatum hyperactivation during imagineother perspective taking in psychopaths, suggesting that individuals with psychopathy are not concerned when adopting others' perspective and may even find others' distress pleasurable. These authors based this supposition on the fact that the ventral striatum and the nucleus accumbens, which are anatomically contiguous, are the sites of positive reinforcement of experiences and involved in pleasure and craving. In fact, when Singer et al. [68] found increased accumbal responses in people watching other people (who were perceived as unfair) receiving punishment, they interpreted it as if those people were feeling pleasure about seeing someone perceived as unfair; in their study, they had observed empathy for the pain of those perceived as fair by both men and women, while women only experienced distress for the pain of people judged as unfair, while men displayed brain activity consistent with pleasure when pain was inflicted to people perceived as unfair. This fact may explain the higher risk for psychopathy of the male gender [68].

In brief, the results of the fMRI study by Decety et al. [67] indicate that psychopaths tend to affectively respond to their own pain, while remaining insensitive to the pain of others through their inability to recruit the neural circuits that controls activate during the imagine-other perspective, leading to a lack of empathic concern.

\section{Classical Aversive Conditioning (Emotional Learning)}

Pavlovian (classical) conditioning is a type of learning in which the conditioned stimulus (CS) indicates the occurrence of a second stimulus, called unconditioned stimulus (US). The US is typically a biologically significant stimulus such as food or pain, which elicits a response from the start that is called the unconditioned response. Usually, the CS elicits no specific response; however, its temporal association to the US is learned and leads to conditioning. After the occurrence of conditioning, the CS elicits the same response as the US, which is now called conditioned response. Classical conditioning procedures differ from operant or instrumental conditioning, in which the behavioural response is strengthened or weakened by its positive or negative consequences, respectively.

Subjects with psychopathy in the context of ASPD showed signal increases in the amygdala and dlPFC during aversive classical conditioning, using odours as US and faces as CS [69]. These results could be referred to significant between-group behavioural distinctions, probably also related to additional task-related efforts (the process may have demanded more resources from ASPD individuals) [69].

Aversive stimulus conditioning failed to elicit a full conditioned response in psychopaths versus controls; this was accompanied by reduced activation of areas of the limbic-prefrontal circuit, including the amygdala, insula, ACC and OFC $[10,11]$. Furthermore, during CS learning, psychopaths showed reduced CS+ from CS- discrimination than controls. This has been interpreted as indicating reduced integration from somatosensory stimuli in the PFC [10].

\section{Lexical Emotional Tasks}

The studies that adopted lexical emotional tasks reported that individuals with psychopathy showed activation changes in different cortical regions compared to controls while performing an emotionally valenced word recognition task $[70,71]$, mainly suggesting a correlation with wrong limbic input of affective stimuli [71]. Lexical decisions involving emotional words may overload those circuits, with subsequent hyperactivation of the cortical and subcortical regions ordinarily involved in adding affect to language. The amygdala is hypothesised to be involved in detecting and evaluating affective stimuli, and coordinating the function of cortical networks during evaluation of the biological significance of affective visual stimuli $[72,73]$. Data confirm that psychopathic subjects are less likely to detect and process emotionally salient stimuli [15], and a primary deficit in the amygdala, as the one that has been shown to exist in psychopathy [71], could contribute to failed performance on the above emotional-valenced lexical memory tasks.

Summarising the evidence, besides the previously hypothesised fear-specific deficit [74], data support a pervasive deficit across various emotions [61]. This general emotional deficit might be related to the often reported lack of empathy in psychopaths, but then, further distinguishing the ability versus propensity for empathy could allow us to further characterise the behaviour of individuals with psychopathy [75].

\section{Morality-Related Tasks}

Early emerging, persistent, destructive antisocial behaviours, socially considered to be amoral or immoral, are core features of psychopathy [76].

Different studies assessed the brain responses while participants made judgements about moral dilemmas [32, 77] or evaluated pictures depicting moral violations [76]. 
Non-psychiatric participants with higher psychopathy scores showed left amygdala hypoactivation during emotional moral decision making. Participants scoring higher on the 'interpersonal' factor of the PCL-R showed hypoactivation of the medial PFC, PCC and angular cortices, which are part of a complex moral circuitry [77].

In an fMRI study with a moral decision paradigm, Harenski et al. [76] reported that participants with psychopathic traits did not show greater activation of the anterior temporal cortex and vmPFC in response to moral versus non-moral versus neutral pictures shown by nonpsychopathic participants, nor did they show the positive association between moral violation severity ratings and amygdala activation that was present in non-psychopaths. Furthermore, psychopaths responded the same way in the anterior temporal cortex to both moral and non-moral pictures, while non-psychopaths activated the anterior temporal cortex more during the moral pictures compared with the non-moral and neutral pictures [76].

Harenski et al. [78] conducted the first fMRI study exclusively focusing on female psychopathy in an incarcerated population, using a moral transgression picture exposure task. They reported that PCL-R scores negatively correlated with unpleasant picture-related activation of the right amygdala and rostral ACC. PCL-R scores also negatively correlated with unpleasant picture-related (depicting moral transgressions) activation of the right temporoparietal junction [78]. They found a negative correlation between rostral ACC activation to unpleasant pictures and PCL-R factor 2 scores. However, whether this negative correlation between PCL-R factor 2 and ACC activity during emotional processing and the aberrant right temporoparietal junction activation related to moral judgements are exclusive of female psychopaths, or are also present in males, remains to be clarified [78].

Compared to controls, during a moral dilemma task, psychopaths showed in BOLD fMRI bilateral hypoactivation of the hippocampus near the hippocampal-amygdalar junction and in a posterior-inferior midbrain circuit involving part of the periaqueductal grey, the locus coeruleus and extending to the cerebellum [32].

\section{Reward-and Social Cognition-Related Tasks}

Different theories underlined that deficits in processing reward and punishment may be linked to the impulsive, aggressive and remorseless behaviours occurring in cases of criminal psychopathy $[5,79,80]$.

The fMRI study by Pujara et al. [81] with a task involving the gain or loss of money showed significantly different correlations between ventral striatal activation and severity of psychopathy. The same study indicated a potentially important interaction between the severity of psychopathy and sensitivity to reward relative to losses [81]. Among the participants in the non-psychopathy group, neither reward nor sensitivity to loss (ventral striatal responses) correlated with the severity of psychopathy, and this was taken to mean adequate behavioural control mechanisms in non-psychopaths. Among those individuals in the psychopathy group, activation differences in the ventral striatum to rewards relative to losses and greater motivation to satisfy bodily needs may be linked to greater levels of impulsive, careless and irresponsible behaviour [81].

Other functional neuroimaging studies using different tasks correlated with social cognition showed that psychopathy is associated with several abnormalities.

In a study focusing on mentalisation in patients from a psychiatric forensic hospital in Germany, former substance-addicted patients were subjected to a test involving the observation of vignettes and the attribution of emotions to the characters of a story while being investigated with fMRI [82]. There were two groups, one with ASPD and psychopathy and the other with no psychopathy, which did not differ in emotion attribution. However, in ASPD psychopaths, emotion attribution was associated with increased activity in the OFC, medial frontal cortex and temporoparietal areas which are related to monitoring and attention, whereas in non-psychopaths it was associated with activation in the mirror neuron system, bilateral supramarginal gyrus and superior frontal gyrus, which are involved in the mentalisation circuitry [82]. In spite of the fact that psychopaths identify other people's emotions similarly to non-psychopaths, they tend to recruit different circuitries in carrying out this task [82].

Mier et al. [83] conducted an fMRI study with a social cognitive task for the investigation of general face processing, emotion recognition and affective theory of mind (ToM) which showed functional changes in key areas of the social-cognitive network in psychopathy. In their study, individuals with psychopathy showed task-independent fusiform hypoactivation, and a lack of activation of the superior temporal sulcus, Brodmann area 44 and amygdala, with increasing demand to recognise feelings/ intentions of depicted persons. These data have been correlated with an impaired automatic matching of emotions and intentions in psychopathy (reduced ability for embodied simulation), and with a deficit in both emotional and motor empathy in psychopathy [83]. The reported reduced connectivity between right superior tem- 
Fig. 2. Consistently reported neural functional changes in the orbitofrontal-limbic network in psychopathy (emotional processing and somatic reaction to emotions and lack of behavioural planning and responsibility). Thicker lines correspond to greater changes.
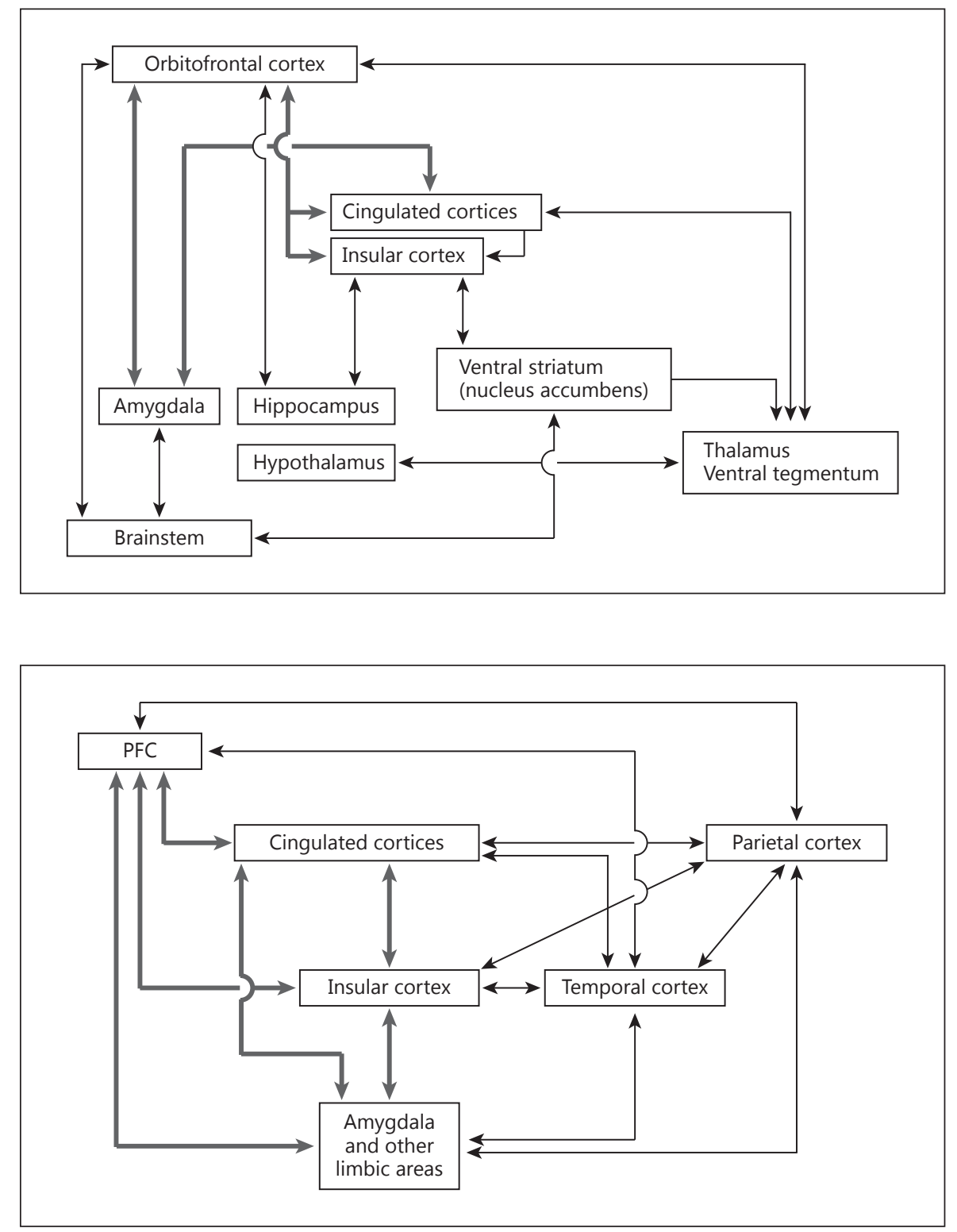

Fig. 3. Consistently reported neural functional changes in the prefrontal-temporalparietal-limbic network in psychopathy (processing and response to emotional stimuli). Thicker arrows indicate greater changes. poral sulcus and left amygdala during affective ToM versus neutral face processing in psychopathy might be correlated with reduced input from the mirror neuron system, which appears per se hypoactive in psychopathy [83].

The fMRI study by Veit et al. [84] with a reaction time competition task linked to reward/punishment of others showed differences between anticipation of high compared to low punishment levels in the inferior OFC, thalamus and pallidum bilaterally in individuals with psychopathy. The same study underlined the absence of ACC, amygdala or prefrontal activity during the anticipa- tion period [84]. Another critical contrast consisted in the comparison between high and low retaliation levels, which showed the most prominent differences in the medial hypothalamus extending to the midbrain in psychopathy, correlated with dyscontrol of aggression [84]. During the observation of the opponent, psychopaths showed increased activation for a suffering compared to a neutral opponent in most areas involved in social cognition and ToM tasks, including occipital areas, inferior and middle temporal areas comprising the superior temporal sulcus, the inferior OFC (Brodmann area 47), insula, dorsomedial $\mathrm{PFC}, \mathrm{vmPFC}$ and right amygdala. When observing 
the opponent being punished, individuals with psychopathy showed increased activation of the dorsomedial PFC and vmPFC, which was positively correlated with impulsiveness and antisocial behaviours [84]. The authors speculated that reactive aggression correlated with antisocial conduct and anger dyscontrol rather than with emotional and interpersonal deficit in psychopathy, and proposed that two distinct brain activation patterns may account for this kind of behavioural traits [84].

\section{Considerations}

A leading model of psychopathy suggests primary dysfunction of a circuit including the amygdala and vmPFC [80]. Another main neuroanatomical model proposes dysfunction in a wider paralimbic network, mainly including the OFC, insula, ACC and PCC, amygdala, parahippocampal gyrus and anterior superior temporal gyrus [85]. A limitation of these models of psychopathy is the failure to discuss the changes occurring in psychopathy in visual and parietal cortex function [47].

Another main question concerns the neurobiological dissociability. Different studies reported distinct neural correlates for each factor and facet score $[43,47,59,62$, 77]. If these findings are related to distinct neurobiological mechanisms for factor 1 and factor 2, the development of new treatments, prevention strategies and outcome may take advantage from separately studying these traits in the context of neurobiological research [43].

This paper underlines that psychopathy correlated with several deficits in cognitive-emotional integration, which can be linked to dysfunctions in both orbitofrontal-limbic (fig. 2) and prefrontal-temporo-parietal-limbic network areas (fig. 3 ) within the context of very complex neurobiological mechanisms.

Neuroimaging data could help psychiatric assessment in forensic settings when used in combination with standard clinical measures [86] and past psychiatric interviews.

As many studies have been conducted on incarcerated individuals, it is unclear whether some of the identified neural functional correlates of psychopathy are to be attributed fully to this condition or rather to psychological and/or mood changes related to merely being imprisoned.

Compared to non-psychopaths, psychopaths showed a higher risk for incarceration (20-25 times), to violent recidivism (4-8 times) and treatment resistance [87]. The adoption of preventive strategies targeted at both early diagnosis [88] and at the adaptive neuroplasticity mechanisms that are prominent in youths may improve care of these individuals [89].

Functional Neuroimaging in Psychopathy

\section{Conclusions}

Individuals with psychopathic traits differ from controls as for task-related activations. Prefrontal deficits are widely present in people with psychopathic traits, who tend to respond with different activation patterns when stimulated with morality-dealing, empathy and ToM-related cues. Emotions and their somatic correlates also differentiate people with psychopathic traits from other individuals; the dysfunctional handling of emotional stimuli in the former appears to be related to cognitive-emotional integration deficit, which can be linked to dysfunctions in both orbitofrontal-limbic and prefrontal-temporo-parietal-limbic network areas. Functional neuroimaging holds promise in elucidating the pathophysiology of psychopathy.

\section{Acknowledgements}

We gratefully acknowledge P. Franco Berti, Director of the P. Alberto Mileno Onlus Foundation, for his work and efforts in patient care and his support in scientific research, and the contribution of the Librarians of the School of Medicine and Psychology of Sapienza University, Ms. Mimma Ariano, Ms. Felicia Proietti, Ms. Ales Casciaro, Ms Teresa Prioreschi, Ms Susanna Rospo, and the late Tiziana Mattei, Librarians of the Sant'Andrea Hospital, School of Medicine and Psychology, Sapienza University, Rome, for rendering precious bibliographical material accessible, as well as their secretary Lucilla Martinelli for her assistance during the writing of the paper.

\section{Disclosure Statement}

In the past 2 years, P.G. has received research support from Lilly and Janssen, participated in Advisory Boards for Lilly, Otsuka, Pfizer and Schering and received honoraria from Lilly; S.F. participated in advisory boards for Pfizer and Lilly and received honoraria from Lilly, Bristol-Myers Squibb, Sigma Tau, Schering and Pfizer.

All other authors of this paper have no relevant affiliations or financial involvement with any organization or entity with a financial interest in or financial conflict with the subject matter or materials discussed in the paper. This includes employment, consultancies, honoraria, stock ownership or options, expert testimony, grants or patents received or pending, or royalties.

References

Neuropsychobiology 2015;72:97-117 115
1 Buzina N: Psychopathy - historical controversies and new diagnostic approach. Psychiatr Danub 2012;24:134-142.

2 Pinel P: Traité médico-philosophique sur l'aliénation mentale, ou la manie. Paris, Richard, Caille \& Ravier, 1799.

3 Lombroso C: L'uomo delinquente, ed 5. Torino, Bocca, 1896.

4 Schneider K: Die psychopathischen Persönlichkeiten. Leipzig, Deuticke, 1923. 
5 Cleckley H: The mask of sanity. St. Louis, Mosby, 1941.

6 American Psychiatric Association: Diagnostic and Statistical Manual of Mental Disorders. Washington, American Psychiatric Association, 1952.

7 American Psychiatric Association: Diagnostic and Statistical Manual of Mental Disorders, ed 5 (DSM-5). Arlington, American Psychiatric Association, 2013.

8 Ogloff JR: Psychopathy/antisocial personality disorder conundrum. Aust NZ J Psychiatry 2006; $40: 519-528$

9 Tang Y, Jiang W, Liao J, Wang W, Luo A: Identifying individuals with antisocial personality disorder using resting-state fMRI. PLoS One 2013;8:e60652.

10 Veit R, Flor H, Erb M, Hermann C, Lotze M, Grodd W, Birbaumer N: Brain circuits involved in emotional learning in antisocial behavior and social phobia in humans. Neurosci Lett 2002;328:233-236.

11 Birbaumer N, Veit R, Lotze M, Erb M, Hermann C, Grodd W, Flor H: Deficient fear conditioning in psychopathy: a functional magnetic resonance imaging study. Arch Gen Psychiatry 2005;62:799-805.

12 Hare RD: The Hare Psychopathy ChecklistRevised, ed 2. Toronto, MultiHealth Systems, 2003.

13 Dadds MR, Perry Y, Hawes DJ, Merz S, Riddell AC, Haines DJ, Solak E, Abeygunawardane AI: Attention to the eyes and fear-recognition deficits in child psychopathy. Br J Psychiatry 2006;189:280-281.

14 Blair RJ, Mitchell DG, Blair KS: The Psychopath: Emotion and the Brain. Oxford, Blackwell, 2005.

15 Blair RJ, Mitchell DG: Psychopathy, attention and emotion. Psychol Med 2009;39:543-555.

16 Hare RD, Neumann CS: The role of antisociality in the psychopathy construct: comment on Skeem and Cooke (2010). Psychol Assess 2010;22:446-454.

17 Skeem JL, Cooke DJ: Is criminal behavior a central component of psychopathy? Conceptual directions for resolving the debate. Psychol Assess 2010;22:433-445.

18 Coid J, Yang M, Ullrich S, Roberts A, Hare $\mathrm{RD}$ : Prevalence and correlates of psychopathic traits in the household population of Great Britain. Int J Law Psychiatry 2009;32:65-73.

19 Millon T, Blaney PH, Davis RD: Oxford Textbook of Psychopathology. New York, Oxford University Press, 1999.

20 Pietrini P, Guazzelli M, Basso G, Jaffe K, Grafman J: Neural correlates of imaginal aggressive behavior assessed by positron emission tomography in healthy subjects. Am J Psychiatry 2000;157:1772-1781.

21 Matsuo K, Nicoletti M, Nemoto K, Hatch JP, Peluso MA, Nery FG, Soares JC: A voxelbased morphometry study of frontal gray matter correlates of impulsivity. Hum Brain Mapp 2009;30:1188-1195.
22 Muñoz LC, Frick PJ: The reliability, stability, and predictive utility of the self-report version of the Antisocial Process Screening Device. Scand J Psychol 2007;48:299-312.

23 Lynam DR, Caspi A, Moffitt TE, Loeber R, Stouthamer-Loeber M: Longitudinal evidence that psychopathy scores in early adolescence predict adult psychopathy. J Abnorm Psychol 2007;116:155-165.

24 Blair RJ: Neuroimaging of psychopathy and antisocial behavior: a targeted review. Curr Psychiatry Rep 2010;12:76-82.

25 Yang Y, Raine A: Prefrontal structural and functional brain imaging findings in antisocial, violent, and psychopathic individuals: a meta-analysis. Psychiatry Res 2009;174:8188.

26 Hare RD: Manual for the Hare Psychopathy Checklist-Revised. Toronto, MultiHealth Systems, 1991.

27 Hart SD, Cox DN, Hare RD: Manual for the Psychopathy Checklist: Screening Version (PCL:SV). Toronto, MultiHealth Systems, 1995.

28 Moher D, Liberati A, Tetzlaff J, Altman DG, PRISMA Group: Preferred reporting items for systematic reviews and meta-analyses: the PRISMA statement. PLoS Med 2009; 6:e1000097.

29 Koenigs M, Baskin-Sommers A, Zeier J, Newman JP: Investigating the neural correlates of psychopathy: a critical review. Mol Psychiatry 2011;16:792-799.

30 Buckner RL, Andrews-Hanna JR, Schacter DL: The brain's default network: anatomy, function, and relevance to disease. Ann NY Acad Sci 2008;1124:1-38.

31 Motzkin JC, Newman JP, Kiehl KA, Koenigs M: Reduced prefrontal connectivity in psychopathy. J Neurosci 2011;31:17348-17357.

32 Pujol J, Batalla I, Contreras-Rodríguez O, Harrison BJ, Pera V, Hernández-Ribas R, Real E, Bosa L, Soriano-Mas C, Deus J, López-Solà M, Pifarré J, Menchón JM, Cardoner N: Breakdown in the brain network subserving moral judgment in criminal psychopathy. Soc Cogn Affect Neurosci 2012;7:917-923.

33 Shulman GL, Fiez JA, Corbetta M, Buckner RL, Miezin FM, Raichle ME, Petersen SE: Common blood flow changes across visual tasks. II. Decreases in cerebral cortex. J Cogn Neurosci 1997;9:648-663.

34 Raichle ME, MacLeod AM, Snyder AZ, Powers WJ, Gusnard DA, Shulman GL: A default mode of brain function. Proc Natl Acad Sci USA 2001;98:676-682.

35 Greicius MD, Krasnow B, Reiss AL, Menon V: Functional connectivity in the resting brain: a network analysis of the default mode hypothesis. Proc Natl Acad Sci USA 2003;100:253258.

36 Fox MD, Snyder AZ, Vincent JL, Corbetta M, Van Essen DC, Raichle ME: The human brain is intrinsically organized into dynamic, anticorrelated functional networks. Proc Natl Acad Sci USA 2005;102:9673-9678.
37 Eslinger PJ, Damasio AR: Severe disturbance of higher cognition after bilateral frontal lobe ablation: patient EVR. Neurology 1985;35: 1731-1741.

38 Damasio AR, Tranel D, Damasio H: Individuals with sociopathic behavior caused by frontal damage fail to respond autonomically to social stimuli. Behav Brain Res 1990;41:8194.

39 Damasio H, Grabowski T, Frank R, Galaburda AM, Damasio AR: The return of Phineas Gage: clues about the brain from the skull of a famous patient. Science 1994;264:11021105; erratum 265:1159.

40 Koenigs M, Kruepke M, Newman JP: Economic decision-making in psychopathy: a comparison with ventromedial prefrontal lesion patients. Neuropsychologia 2010;48: 2198-2204.

41 Basoglu C, Semiz U, Oner O, Gunay H, Ebrinc S, Cetin M, Sildiroglu O, Algul A, Ates A, Sonmez G: A magnetic resonance spectroscopy study of antisocial behavior disorder, psychopathy and violent crime among military conscripts. Acta Neuropsychiatr 2008;20:7277.

42 Ly M, Motzkin JC, Philippi CL, Kirk GR, Newman JP, Kiehl KA, Koenigs M: Cortical thinning in psychopathy. Am J Psychiatry 2012;169:743-749.

43 Philippi CL, Pujara MS, Motzkin JC, Newman J, Kiehl KA, Koenigs M: Altered resting-state functional connectivity in cortical networks in psychopathy. J Neurosci 2015;35:60686078.

44 Larson CL, Baskin-Sommers AR, Stout DM, Balderston NL, Curtin JJ, Schultz DH, Kiehl KA, Newman JP: The interplay of attention and emotion: top-down attention modulates amygdala activation in psychopathy. Cogn Affect Behav Neurosci 2013;13:757-770.

45 Corbalán F, Beaulieu S, Armony JL: Emotion regulation in bipolar disorder type I: an fMRI study. Psychol Med 2015;45:2521-2531.

46 Freeman SM, Clewett DV, Bennett CM, Kiehl KA, Gazzaniga MS, Miller MB: The posteromedial region of the default mode network shows attenuated task-induced deactivation in psychopathic prisoners. Neuropsychology 2015;29:493-500.

47 Juárez M, Kiehl KA, Calhoun VD: Intrinsic limbic and paralimbic networks are associated with criminal psychopathy. Hum Brain Mapp 2013;34:1921-1930.

48 Kiehl KA, Smith AM, Mendrek A, Forster BB, Hare RD, Liddle PF: Temporal lobe abnormalities in semantic processing by criminal psychopaths as revealed by functional magnetic resonance imaging. Psychiatry Res 2004; 130:297-312.

49 Blair RJ: The emergence of psychopathy: implications for the neuropsychological approach to developmental disorders. Cognition 2006;101:414-442. 
50 Dadds MR, Jambrak J, Pasalich D, Hawes DJ, Brennan J: Impaired attention to the eyes of attachment figures and the developmental origins of psychopathy. J Child Psychol Psychiatry 2011;52:238-245.

51 Newman JP, Lorenz AR: Response modulation and emotion processing: implications for psychopathy and other dysregulatory psychopathology; in Davidson RJ (ed): Handbook of Affective Sciences. New York, Oxford University Press, 2003, pp 904-929.

52 Ekman P: Darwin and facial expression: a century of research in review. Cambridge, Malor, 2006.

53 Carlson NR: Physiology of behaviour, ed 10. Boston, Allyn \& Bacon, 2010.

54 Adolphs R: Neural systems for recognizing emotion. Curr Opin Neurobiol 2002;12:169177.

55 Ekman P, Friesen WV: Pictures of Facial Affect. Palo Alto, Consulting Psychologists, 1976.

56 Beaupré MG, Hess U: Cross-cultural emotion recognition among Canadian ethnic groups. J Cross Cult Psychol 2005;36:355-370.

57 Deeley Q, Daly E, Surguladze S, Tunstall N, Mezey G, Beer D, Ambikapathy A, Robertson D, Giampietro V, Brammer MJ, Clarke A, Dowsett J, Fahy T, Phillips ML, Murphy DG: Facial emotion processing in criminal psychopathy. Preliminary functional magnetic resonance imaging study. Br J Psychiatry 2006;189:533-539.

58 Decety J, Skelly LR, Kiehl KA: Brain response to empathy-eliciting scenarios involving pain in incarcerated individuals with psychopathy. JAMA Psychiatry 2013;70:638-645.

59 Decety J, Skelly L, Yoder KJ, Kiehl KA: Neural processing of dynamic emotional facial expressions in psychopaths. Soc Neurosci 2014 9:36-49.

60 Dawel A, O’Kearney R, McKone E, Palermo R: Not just fear and sadness: meta-analytic evidence of pervasive emotion recognition deficits for facial and vocal expressions in psychopathy. Neurosci Biobehav Rev 2012;36: 2288-2304.

61 Contreras-Rodríguez O, Pujol J, Batalla I, Harrison BJ, Soriano-Mas C, Deus J, LópezSolà $\mathrm{M}$, Macià $\mathrm{D}$, Pera $\mathrm{V}$, Hernández-Ribas $\mathrm{R}$, Pifarré J, Menchón JM, Cardoner N: Functional connectivity bias in the prefrontal cortex of psychopaths. Biol Psychiatry 2015;78: 647-655.

62 Bauer RM: Physiologic measures of emotion J Clin Neurophysiol 1998;15:388-396.
63 Bradley MM, Cuthbert BN, Lang PJ: Picture media and emotion: effects of a sustained affective context. Psychophysiology 1996;33: 662-670.

64 Lang PJ, Bradley MM, Cuthbert BN: Emotion, attention, and the startle reflex. Psychol Rev 1990;97:377-395.

65 Müller JL, Sommer M, Wagner V, Lange K, Taschler H, Röder CH, Schuierer G, Klein HE, Hajak G: Abnormalities in emotion processing within cortical and subcortical regions in criminal psychopaths: evidence from a functional magnetic resonance imaging study using pictures with emotional content. Biol Psychiatry 2003;54:152-162.

66 Weber T, Sommer M, Hajak G, Müller J: Die emotionale Informationsverarbeitung bei $\mathrm{Pa}$ tienten mit einer dissozialen Persönlichkeitsstörung vom Subtyp der 'Psychopathy' nach Hare. Psychiatr Prax 2004;31(suppl 1):S68-S69.

67 Decety J, Chen C, Harenski C, Kiehl KA: An fMRI study of affective perspective taking in individuals with psychopathy: imagining another in pain does not evoke empathy. Front Hum Neurosci 2013;7:489.

68 Singer T, Seymour B, O’Doherty JP, Stephan KE, Dolan RJ, Frith CD: Empathic neural responses are modulated by the perceived fairness of others. Nature 2006;439:466-469.

69 Schneider F, Habel U, Kessler C, Posse S, Grodd W, Müller-Gärtner HW: Functional imaging of conditioned aversive emotional responses in antisocial personality disorder. Neuropsychobiology 2000;42:192-201.

70 Intrator J, Hare R, Stritzke P, Brichtswein K, Dorfman D, Harpur T, Bernstein D, Handelsman L, Schaefer C, Keilp J, Rosen J, Machac J: A brain imaging (single photon emission computerized tomography) study of semantic and affective processing in psychopaths. Biol Psychiatry 1997;42:96-103.

71 Kiehl KA, Smith AM, Hare RD, Mendrek A, Forster BB, Brink J, Liddle PF: Limbic abnormalities in affective processing by criminal psychopaths as revealed by functional magnetic resonance imaging. Biol Psychiatry 2001;50:677-684.

72 Pessoa L: Emotion and cognition and the amygdala: from 'what is it?' to 'what's to be done?'. Neuropsychologia 2010;48:34163429.

73 Pessoa L, Adolphs R: Emotion processing and the amygdala: from a 'low road' to 'many roads' of evaluating biological significance. Nat Rev Neurosci 2010;11:773-783.

74 Marsh AA, Blair RJ: Deficits in facial affect recognition among antisocial populations: a meta-analysis. Neurosci Biobehav Rev 2008; 32:454-465
75 Keysers C, Gazzola V: Dissociating the ability and propensity for empathy. Trends Cogn Sci 2014; 18:163-166.

76 Harenski CL, Harenski KA, Shane MS, Kiehl KA: Aberrant neural processing of moral violations in criminal psychopaths. J Abnorm Psychol 2010;119:863-874.

77 Glenn AL, Raine A, Schug RA: The neural correlates of moral decision-making in psychopathy. Mol Psychiatry 2009;14:5-6.

78 Harenski CL, Edwards BG, Harenski KA, Kiehl KA: Neural correlates of moral and non-moral emotion in female psychopathy. Front Hum Neurosci 2014;8:741.

79 Lykken DT: A study of anxiety in the sociopathic personality. J Abnorm Psychol 1957; 55:6-10.

80 Blair RJ: The amygdala and ventromedial prefrontal cortex: functional contributions and dysfunction in psychopathy. Philos Trans R Soc Lond B Biol Sci 2008;363:2557-2565.

81 Pujara M, Motzkin JC, Newman JP, Kiehl KA, Koenigs M: Neural correlates of reward and loss sensitivity in psychopathy. Soc Cogn Affect Neurosci 2014;9:794-801.

82 Sommer M, Sodian B, Döhnel K, Schwerdtner J, Meinhardt J, Hajak G: In psychopathic patients emotion attribution modulates activity in outcome-related brain areas. Psychiatry Res 2010;182:88-95.

83 Mier D, Haddad L, Diers K, Dressing H, Meyer-Lindenberg A, Kirsch P: Reduced embodied simulation in psychopathy. World J Biol Psychiatry 2014;15:479-487.

84 Veit R, Lotze M, Sewing S, Missenhardt H, Gaber T, Birbaumer N: Aberrant social and cerebral responding in a competitive reaction time paradigm in criminal psychopaths. NeuroImage 2010;49:3365-3372.

85 Kiehl KA: A cognitive neuroscience perspective on psychopathy: evidence for paralimbic system dysfunction. Psychiatry Res 2006;142: 107-128.

86 Sartori G, Pellegrini S, Mechelli A: Forensic neurosciences: from basic research to applications and pitfalls. Curr Opin Neurol 2011;24 371-377.

87 Kiehl KA, Hoffman MB: The criminal psychopath: history, neuroscience, treatment, and economics. Jurimetrics 2011;51:355-397.

88 Lilienfeld SO, Andrews BP: Development and preliminary validation of a self-report measure of psychopathic personality traits in noncriminal populations. J Pers Assess 1996;66: 488-524.

89 Anderson NE, Kiehl KA: Psychopathy: developmental perspectives and their implications for treatment. Restor Neurol Neurosci 2014 $32: 103-117$. 